\title{
La trama racializada de lo visual. Una aproximación a las representaciones grotescas de los afroargentinos
}

María de Lourdes Ghidoli

\section{(2) OpenEdition \\ Journals}

Electronic version

URL: http://journals.openedition.org/corpusarchivos/1744

DOI: 10.4000/corpusarchivos. 1744

ISSN: 1853-8037

Publisher

Diego Escolar

\section{Electronic reference}

María de Lourdes Ghidoli, « La trama racializada de lo visual. Una aproximación a las representaciones grotescas de los afroargentinos », Corpus [En línea], Vol 6, No 2 | 2016, Publicado el 29 diciembre 2016, consultado el 19 abril 2019. URL : http://journals.openedition.org/corpusarchivos/1744 ; DOI :

10.4000/corpusarchivos.1744

This text was automatically generated on 19 April 2019.

Licencia Creative Commons: Atribución-NoComercial 2.5 Argentina (CC BY-NC 2.5 AR) 


\title{
La trama racializada de lo visual. Una aproximación a las representaciones grotescas de los afroargentinos
}

\author{
María de Lourdes Ghidoli
}

\section{Introducción}

1 Hacia fines del siglo XIX se consolida el proyecto de nación argentina sustentado en la homogeneidad racial (blanco) y cultural (europeo/estadounidense). La homogeneidad era considerada una característica necesaria para la conformación de una nación pues se asociaba con la capacidad de progreso, vinculando la heterogeneidad con un estadio primitivo (Quijada 2000, p. 23). En este sentido, la blanquitud fue/es pensada como un rasgo civilizatorio intrínseco a una identidad nacional. Las preguntas disparadoras de este debate incitan a tratar de comprender cómo se construyó/construye la nación en imágenes, por qué ciertas representaciones visuales se erigen en 'verdaderas' para referirse a la nación e indagar acerca de la funcionalidad de las mismas en este proceso de homogeneización, especialmente a través de su difusión en medios disponibles (sistema educativo, prensa periódica, circuitos de creación y exposición artística, literatura).

Considerando que el proceso de producción de sentido que comporta la ideología de la blanquitud llevó a la desmarcación del grupo de población de ascendencia africana y a su asimilación a lo blanco europeo nacional, constituyendo a negros y mulatos como una alteridad pre-histórica, menospreciando su participación en la historia oficial y clausurando su lugar en el imaginario social y en la memoria colectiva de los argentinos (Geler 2010, p. 19), el estudio en torno a la construcción del imaginario social acerca de los afroargentinos se vuelve imprescindible.

3 En una investigación previa propuse como hipótesis que la construcción y el empleo reiterado de estereotipos se erigió como una de las estrategias del proceso de 
invisibilización sufrido por la población afroargentina gestado a partir de las narrativas e imágenes dominantes que afirmaban la supuesta desaparición de la población de origen africano en el país y la irremediable blanquitud argentina, operaciones discursivas y visuales complementarias desplegadas a lo largo del siglo XIX y principios del siglo XX (Ghidoli 2016). De la aparentemente simple observación del corpus visual disponible emergieron los núcleos iconográficos que presenté como representaciones estereotípicas de los descendientes de africanos, con énfasis en la producción visual de Buenos Aires. Esta estereotipación racial abarca desde la (supuestamente inerme) fijación en roles sociales o laborales hasta las insultantes representaciones grotescas: criados, bufones, adeptos al régimen rosista, tipos sociales pintorescos. Sin embargo, desde el campo de la historia del arte poco se ha dicho sobre este tipo de imágenes y, en ocasiones, en la descripción de obras del siglo XIX que involucran gran cantidad de personajes se ha omitido mencionar la presencia de los/as afroporteño/as en ellas. De allí la inclusión del adverbio en la expresión "la aparentemente simple observación" que usé más arriba pues revela los modos de ver puestos en juego en nuestro entorno. Surgen de aquí dos interrogantes: 1) $i$ Creemos que el lugar que se les ha asignado a los afroargentinos en las imágenes tiene su correlato en la vida cotidiana?, cuya respuesta afirmativa traería aparejados asuntos relacionados con concepciones jerárquicas del orden de lo racial y/o lo social. O tal vez, ante la ausencia de reclamos de gran parte de la sociedad mayor, 2) ¿la visión de estas imágenes nos deja inmutables pues consideramos que los descendientes de africanos no formaron/forman parte de nuestra sociedad? Ambas respuestas positivas resultarían perturbadoras. Si como expresa Berger (2005, p. 14) "nunca miramos sólo una cosa; siempre miramos la relación entre las cosas y nosotros mismos", la eficacia del proceso de invisibilización ya aludido se torna elocuente.

4 Tres de los núcleos iconográficos propuestos en aquella investigación persisten, aun hasta nuestros días, con variaciones que no implican un cambio sustancial en su representación. Sin embargo, en este debate haré foco en las representaciones grotescas pues han sufrido transformaciones radicales en el siglo que media entre la década de 1840 y la de 1940.

\section{La trama de lo visual: conceptos entrelazados}

Esta indagación se asienta en el cruce de la historia del arte, la historia cultural y los estudios de la cultura visual. Estos últimos se han tornado desde la década de 1990 en un campo de reflexión que se relaciona de forma problemática con la historia del arte tradicional asentada en valores estéticos presupuestos como universales (Moxey 2003). Tal enfoque implica concentrarse en los actos de ver, las prácticas de la visualidad que producen significados culturales, sociales y políticos, y se erigen en un medio de comunicación sumamente efectivo. Vale decir, correrse de un estudio de la visualidad 'pura' y examinar la visión no como algo psicofisiológicamente dado sino como un proceso visual que tiene una ligazón histórico-cultural específica ${ }^{2}$ en la cual la noción de representación es primordial. En este sentido, desde la historia cultural Marin (2009 [1981], p. 137) desarrolló una teoría que dio cuenta del sentido doble que conlleva el término: una dimensión transitiva o transparente según la cual se sustituye a otra cosa, se evoca una ausencia, implica un efecto de presencia. Por otro, una dimensión reflexiva u opaca que consiste en tener la capacidad de exhibirse y con ello de constituir a un sujeto 
por reflexión del dispositivo representativo. Como veremos, para las imágenes que se propondrán en el debate, esta doble vertiente será sumamente pertinente.

6 A su vez, en este escrito centrado en imágenes racializadas de individuos de ascendencia africana que funcionan al interior de una cultura visual, asumida como un lugar de interacción social, los conceptos de invisibilización, estereotipo y grotesco se encadenan necesariamente con el de representación. Por ello, creo conveniente extenderme en su caracterización.

Como he mencionado previamente, argumento que la estereotipación se convirtió en una estrategia poderosa en el proceso de invisibilización sufrido por la población afrodescendiente en Argentina. Por lo cual resulta decisivo desentrañar las estrategias de construcción de esas representaciones estereotipadas, fijadas, 'signos de diferencia cultural/histórica/racial' (Bhabha 2002, p. 92). Esta práctica representacional significante reduce a las personas a unos pocos, simples y esenciales rasgos que se pretenden fijados por la naturaleza (Hall 2010, p. 257). Los estereotipos se tornan en una forma de ordenamiento de los datos complejos y caóticos del mundo que permiten dar sentido a una sociedad a través de generalizaciones, modelizaciones y 'tipificaciones'. Sin embargo, su importancia reside en quién los controla y define, a qué intereses sirven (Dyer 2006, p. 356). De manera resumida, los estereotipos a) reducen a los miembros de un grupo a unos pocos rasgos (físicos, morales, de conducta) simples, de fácil comprensión, recordables y que busca hacerlos inmutables; b) se estructuran entre opuestos binarios, dividiendo lo normal y aceptable de lo que no lo es y fijando simbólicamente límites que excluyen a todos aquellos que no caen dentro de 'la norma'; c) se desarrollan principalmente cuando existen desigualdades de poder; d) la efectividad de la estereotipación reside en que invoca la existencia de un consenso al interior de la sociedad en la cual se la implementa; e) la repetición de los estereotipos alimenta y da forma al imaginario social; f) tienen consecuencias palpables en la vida cotidiana.

\section{Lo grotesco en escena}

8 Abordaré brevemente esta categoría, en principio estética pero también cargada ideológicamente, siguiendo a tres autores de entre los muchos que han teorizado sobre ella. Su empleo en la cultura occidental, a partir de la segunda mitad del siglo XVII, ha elegido frecuentemente como sujetos de exageración y deformación a personas pertenecientes a otras culturas o razas, como modo de despersonalización y degradación. Bajtin ha señalado que, analizada desde un canon estético clasicista, la categoría de lo grotesco y su anclaje en la visión carnavalesca del 'mundo al revés', propia de la edad media y el renacimiento, muta en ambivalencia horrorosa e incomprensible para la ideología de la ilustración (2003, p. 65). Por su parte, Thomson (1972) se acerca al concepto en obras y autores que van del siglo XVIII en adelante, vale decir desde una estética clasicista. Por ello en lo que refiere a la recepción de las obras, el autor define lo grotesco como un choque irresuelto entre reacciones incompatibles, la risa por un lado y el horror o la repugnancia por el otro. Asimismo Harpham (1982) trabaja sobre los efectos en los receptores y propone que, ante la presencia de una entidad (imagen, objeto o experiencia) se nos impone un intervalo de lo grotesco, una especie de estadio "purgatorial" que paraliza nuestra comprensión. En ese estadio el objeto o la experiencia aparece como una mixtura y/o distorsión de formas o como una yuxtaposición de formas incongruentes, que no calzan en nuestros moldes de lo conocido (y finalmente 
reconocido). El espectador a menudo no es consciente de ese intervalo debido a su brevedad pues rápidamente la memoria y la anticipación lo asocian con formas reconocibles $y$, a la postre, tranquilizadoras.

\section{Mutaciones de los estereotipos grotescos}

9 En este trabajo haré foco en dos grupos de imágenes: el primero vinculado con la representación de los bufones del período rosista y el segundo correspondiente a historietas de la década de 1930. Sin embargo, quisiera advertir que plantearé aquí sólo una primera aproximación a la indagación de las mutaciones de lo negro grotesco en Argentina que se advierten al comparar ambos grupos. Un enfoque asentado en los estudios de la cultura visual entraña poner atención en imágenes diversa índole, ya no sustentadas en valores estéticos universales y convierte a estos objetos en actores cruciales en la escena histórica considerada a partir de su especificidad visual. Esto trae aparejada la ampliación del corpus visual a examinar (ilustraciones de la prensa, fotografías etnográficas, juguetes, objetos decorativos, etc.), incorporando, en nuestro caso, las historietas.

El primer grupo -el de los bufones de Rosas- lo he analizado de manera extensa en otro escrito (Ghidoli 2016), por lo cual me referiré a él sólo brevemente. Juan Manuel de Rosas dejó profunda huella en la historia del país no sólo porque gobernó la provincia de Buenos Aires durante casi 23 años -entre 1829 y 1832 primero, y entre 1835 y 1852 después- sino también porque fue convertido, por quienes finalmente lograron vencerlo y destituirlo, en eje fundamental sobre el cual se asentaron muchas de las disputas posteriores a su caída. Sus adversarios lo retrataban como un señor feudal, rodeado de una corte a la manera española, en la cual no podían faltar bufones, en este caso de ascendencia africana debido a su cercanía con negros y mulatos. Este motivo resultó en un elemento útil para dar cuenta de la barbarie, tanto de Rosas como de los descendientes de africanos. Como señalamos, la manera en que se recepciona una imagen grotesca está en gran medida relacionada con la respuesta generalmente ambivalente (horror, risa) provocada por el descolocamiento o la incomodidad racional que genera este tipo de imágenes. No obstante, dentro del estereotipo grotesco, existen diferencias asociadas a la pérdida o no de un anclaje con lo humano. Si pensamos en una obra como El negro Bigua (c. 1841) (ver imagen 1) lo humano está presente, a pesar de las correspondientes deformidades del cuerpo. No sólo se trata de un personaje verosímil y/o real, teniendo en cuenta la controversia que pueden presentar los relatos e imágenes de los adversarios de Rosas, sino que la misma representación podría tratarse de un retrato aunque fuera ficticio. 


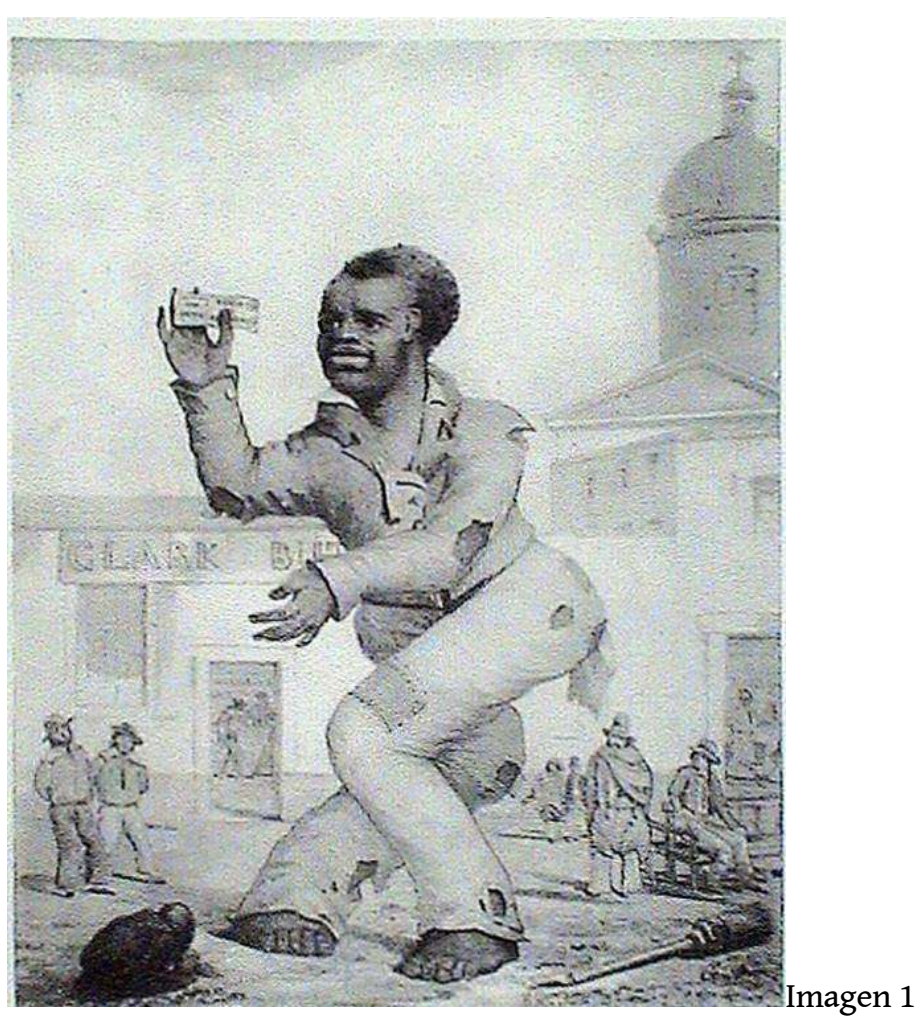

11 Entrado el siglo XX lo grotesco negro muta drásticamente y sólo quedan algunos rastros de lo humano. A lo largo del siglo XIX encontramos un corpus visual importante que figura a los afroporteños por medio de distintas técnicas y soportes: óleos, grabados, ilustraciones de revistas. En Argentina, el cambio de siglo trajo consigo condiciones técnicas de posibilidad de la imagen impresa que permitieron la propagación de publicaciones ilustradas (Szir 2009). Y es allí donde proliferaron las representaciones, principalmente cómicas y grotescas, de los negros. Un caso paradigmático es el de la revista Caras y Caretas. Frigerio señala que

"el negro" de Caras y Caretas (tanto el de las notas sobre la realidad cotidiana como el de las propagandas y chistes) es "una tipificación", a la vez una categoría social y un símbolo cultural. Es un "modelo de" que a la gente de la época le ratificaba las características socialmente asignadas a "un negro" y un "modelo para" la interacción que enseñaba o reafirmaba cómo interactuar con uno, ubicando a cada actor en un orden social, en transformación pero aún jerarquizado en términos raciales (2011, p. 153).

Para la década de 1930 las imágenes de afrodescendientes habían disminuido en la revista. Pero hacen su aparición en otras publicaciones en formato historieta, género que comenzaba a imponerse y que implicaba una secuencialidad y la presencia de personajes fijos. En este escrito daré cuenta de tres: "El negrito Alelí" (ver imagen 2), "Paragüitas. El inventor del trabajo" (ver imagen 3) y "Tutú y su pandilla" (ver imagen 4) que formaron parte de Figuritas. La revista del escolar entre 1937-38. Si observamos con atención estas imágenes encontramos algunas diferencias entre el negrito Alelí, protagonista de su propia historieta y los caracteres secundarios de las otras dos series. Para estas últimas, respecto de los personajes negros que aparecen junto a Paragüitas y Tutú, podríamos hablar de casi una animalización de sus rasgos. Yuplim fue traído de África a Buenos Aires por Paragüitas quien además lo bautizo con tal nombre. Por su parte Carbonilla, amigo de Tutú, parece tener un origen local a pesar de expresarse en lengua bozal. En este punto es oportuno señalar que estas historietas tienen un mismo autor: Rosario Marino ${ }^{3}$ a quien le 
pareció conveniente que ambos personajes fueran casi idénticos diferenciándose apenas por la vestimenta que llevan (ver imagen 5 y 6 ).
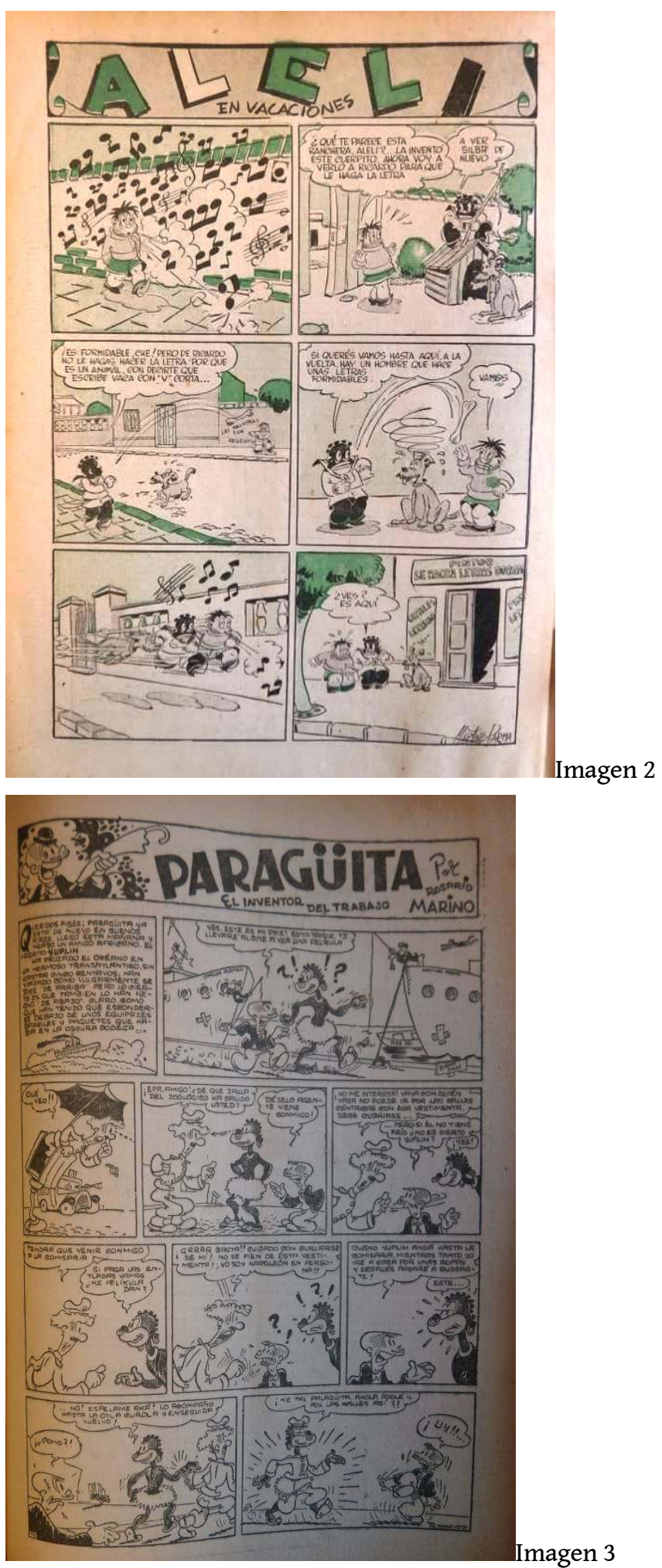


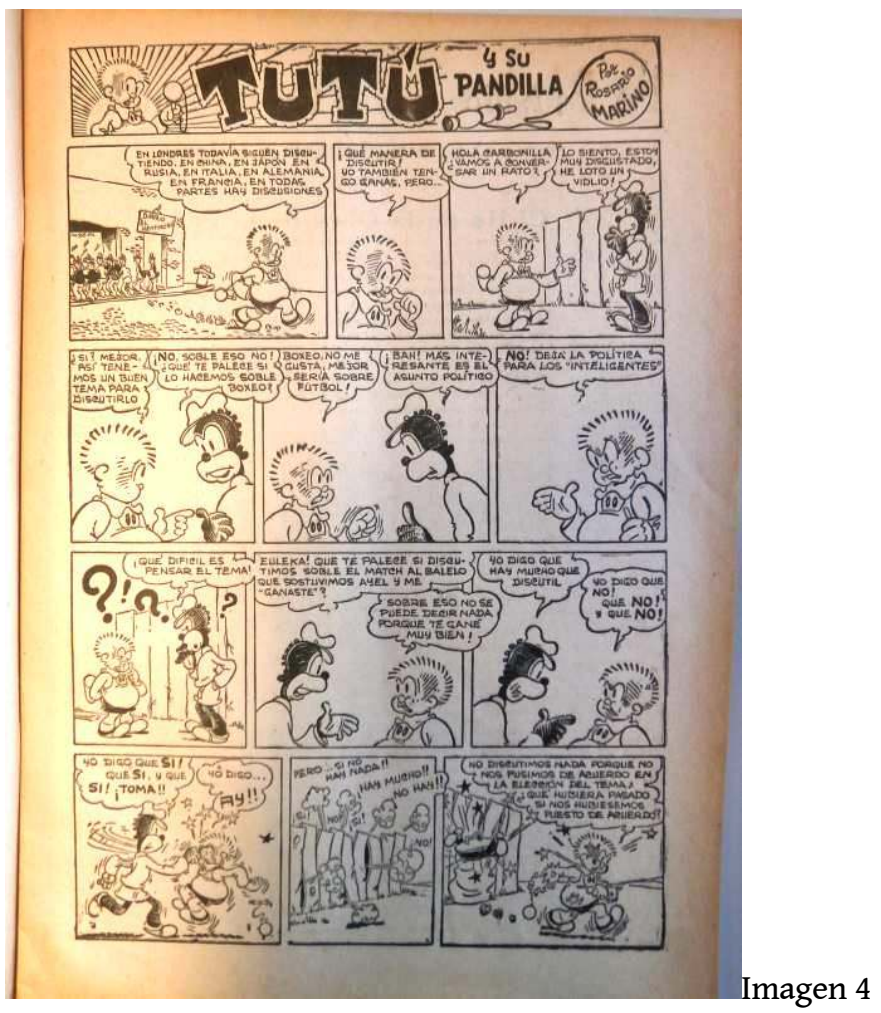

Por otro lado, la representación de Alelí, creado por Martínez Parma, ${ }^{4}$ remite a una corporalidad humana, sin embargo, sumamente simplificada aun para lo que se define como un estereotipo. Lo grotesco ya no pasa por una deformidad racializada como en el caso de los bufones de Rosas. La economía de recursos empleados para representar a los negros en esta historieta está marcada por los labios desmesurados, rojos cuando hay color, las motas individuales implantadas en la redondez de la cabeza, los ojos como dos esferas blancas con un punto negro en el centro (ver imagen 7). El rostro que en Biguá podía haber respondido a un retrato troca aquí en una máscara. En la imagen que se crea de Alelí podemos observar que no sólo se recurre al rostro como máscara sino que el personaje además usa guantes blancos. Tal elemento de caracterización, sin motivación evidente en el ámbito local, permite conectarlo con las personificaciones de los blackface minstrelsy estadounidenses y con los dibujos animados como los de Disney, por ejemplo. ${ }^{5}$ En otro trabajo (Ghidoli 2009) he abordado el motivo iconográfico del bufón rastreando su supervivencia en la cultura occidental y deteniéndome en los momentos de activación de la imagen: antigüedad (sátiros que acompañan a Dionisos), siglos XVI-XVIII (el Arlequín de la Commedia dell'Arte) y siglo XIX (Jim Crow y Biguá). Estas activaciones tuvieron lugar en horizontes histórico-cultural específicos que permitieron poner de relieve el quiebre fundamental que se produjo en la concepción de los afrodescendientes a partir del siglo XIX en el marco del avance del racismo científico. Al respecto Gates Jr, indagando en la figura de Jim Crow y los minstrel performers, ha encontrado una continuidad con la figura del arlequín cuya máscara porta rasgos fenotípicos que la conectan con África. No obstante existen diferencias fundamentales en las características morales e intelectuales de uno y otro, que se vinculan a su condición racial: "la nobleza inherente de Arlequín se va transformando gradualmente en la innoble figura del minstrel negro" (Gates Jr. 1987, p. 52). Todos ellos -Biguá, Eusebio, Alelí, Yuplim, Carbonilla, los minstrels- comparten el rol de bufones o entretenedores, aquellos cuya función es divertir a otros, con el rasgo fundamental de ser personajes fijados a un referente africano. 


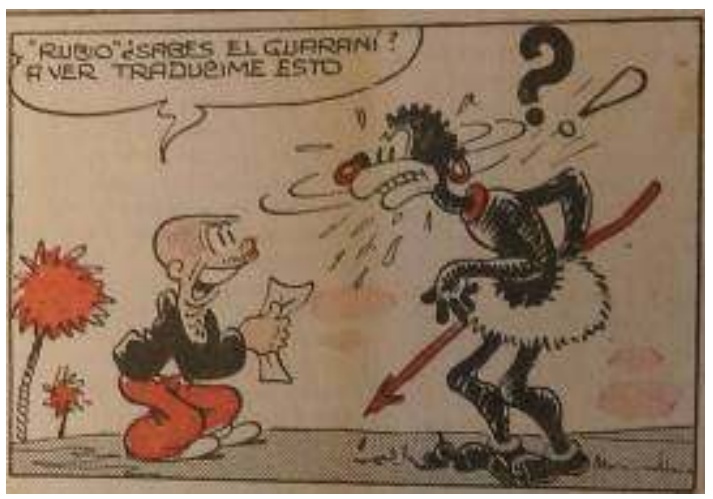

Imagen 5
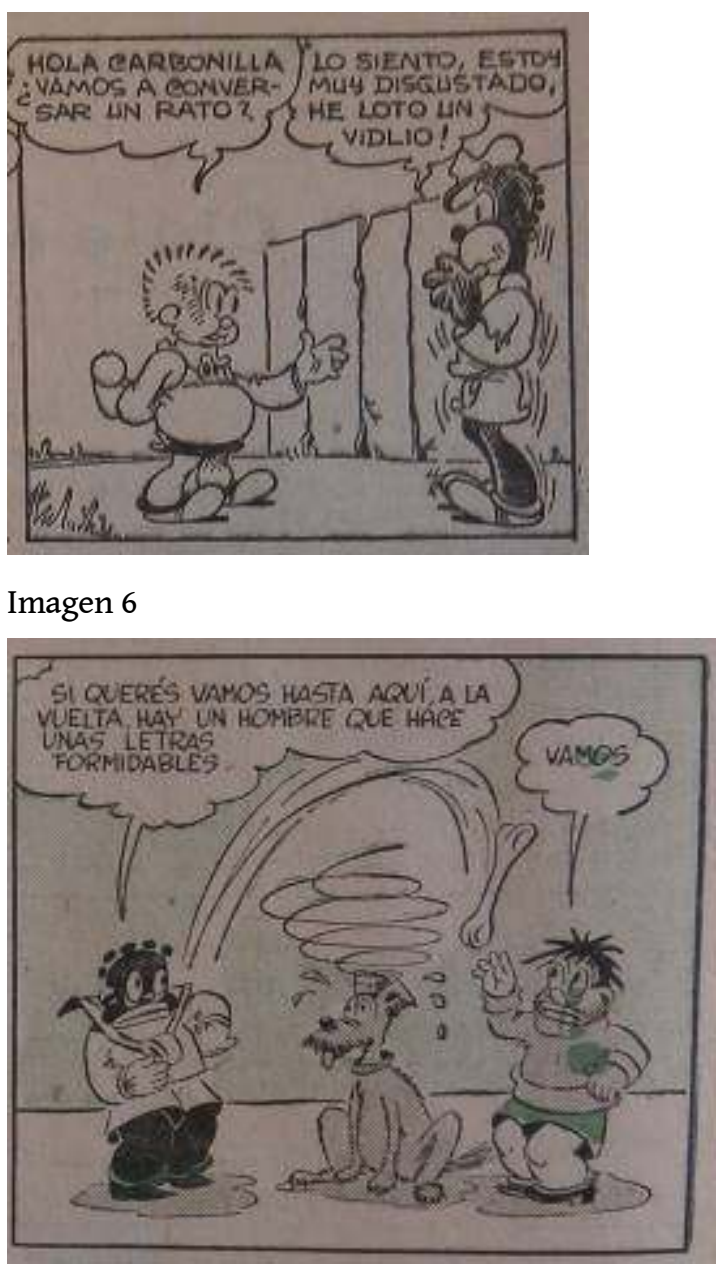

Imagen 7

Los personajes de historietas de la tercera década del siglo XX parecen proponer una secuela en el derrotero de la imagen del bufón. Partiendo de la ya mencionada doble dimensionalidad de la representación propuesta por Marin, se abren vías de exploración variadas y complementarias que sólo esbozaré en este momento. En primer lugar analizar las imágenes en relación con aquello a lo cual refieren en nuestro caso personas de ascendencia africana en un contexto local y temporal. Por otro, indagar desde la propia materialidad por la cual se impone una imagen y constituye al sujeto que mira (Chartier 1996, p. 78). Es decir, las técnicas/tecnologías con que fueron construidas, las intenciones que supone su existencia, los modos de circulación que tuvieron, el público para el cual 
fueron concebidas. Como ejemplo, el modo en que se figuran los afrodescendientes, un grotesco llevado al extremo, y la tecnología empleada para la ejecución de la historieta concomitante a una circulación difusa de estas imágenes concebidas para un público infantil nos exhortan a indagar sobre su anclaje en ese momento histórico específico. Asimismo será clave poner en relación las imágenes y la narración que conlleva la historieta, tanto en el rol que juegan estos personajes como en la forma en la que se los hace hablar. En el mismo sentido, las preguntas que suscita su inclusión como espacio de diversión y de descanso del aprendizaje escolar en una revista pensada como recurso didáctico para los contenidos enseñados en las aulas entrañan aspectos vinculados con la construcción de un público infantil en consonancia con la idea de nación consolidada desde fines del siglo XIX.

\section{A modo de cierre}

18 Ciertamente queda mucho para analizar respecto de la radical mutación en las imágenes grotescas. Pero como anticipé se trata de un trabajo aun en elaboración el cual sólo pretendí esbozar en este debate. No obstante es posible bosquejar algunas conclusiones. Partimos de imágenes como las de los bufones de Rosas, en las que se hace uso de los descendientes de africanos como ejemplificadores de la barbarie tanto del adversario político como de los propios afroporteños. Se buscaba establecer una relación de proximidad para destilar el odio político coyuntural y dar forma a concepciones y percepciones de la negritud argentina. Este nexo entre imágenes y política, a pesar de su carácter grotesco, implicó representaciones sustentadas en la existencia de una población afrodescendiente local.

De manera diferente las historietas de la década de 1930 acudieron a estereotipos 'importados'. Quisiera distinguirlos de esta manera pues si bien las representaciones visuales de afroporteños en el siglo XIX en muchos casos se vinculaban con imágenes provenientes de la cultura visual occidental (Ghidoli 2016) no fueron trasplantadas $\sin$ más sino que sus inscripciones estuvieron mediadas por el contexto local. ${ }^{6}$ Considero que la elección de este repertorio iconográfico está atravesada por el proceso de invisibilización que para ese momento había demostrado su eficacia, figurando a los afrodescendientes por medio de representaciones que los extranjeriza y, atrozmente, los aleja de lo humano.

20 Si las imágenes racializadas implican una desviación de la blanquitud nacional, los estereotipos grotescos racializados suponen además una desviación de lo normal, aun al interior del propio grupo de pertenencia. Sin embargo, las historietas de la década del 30 dan cuenta de otras desviaciones aún más preocupantes que buscan animalizar a los miembros de un grupo de población. Será oportuno entonces develar de qué manera operan en la construcción incesante de la nación. 


\section{BIBLIOGRAPHY}

Bajtin, M. (2003). La cultura popular en la Edad Media y el Renacimiento. El contexto de François Rabelais. Madrid: Alianza.

Berger, J. (2005). Modos de ver. Barcelona: Gustavo Gili.

Bhabha, H. (2002). El Lugar de la Cultura. Buenos Aires: Manantial.

Chartier, R. (1996). Escribir las prácticas. Foucault, de Certeau, Marin. Buenos Aires: Manantial.

Dyer, R. (2006[1977]). Stereotyping. En M. G. Durham y D. EM. Kellner, Media and Cultural Studies: keywords. (pp. 353-365). Blackwell.

Frigerio, A. (2011). "Sin otro delito que el color de su piel". Imágenes del "negro" en la revista Caras y Caretas (1900-1910)”. En F. Guzmán y L. Geler (eds.), Cartografías Afrolatinoamericanas. Perspectivas situadas para análisis transfronterizos. (pp. 151-172). Buenos Aires: Biblos.

Gates Jr, H. (1987). Figures in black: words, signs and the "racial" self. New York: Oxford University Press.

Geler, L. (2015). Negritud, invasión y peligro en la Buenos Aires de 1945: un análisis de las representaciones raciales a través de la publicidad de la obra teatral Sangre negra. En: P. García Jordán (ed.), El mundo latinoamericano como representación, siglos XIX-XX. (pp. 199-225). Barcelona: Edicions Universitat Barcelona.

Geler, L. (2010). Andares negros, caminos blancos. Afroporteños, Estado y Nación Argentina a fines del siglo XIX. Rosario: Prohistoria/TEIAA

Ghidoli, M. (2016). Estereotipos en negro. Representaciones y autorrepresentaciones de afroporteños en el siglo XIX. Rosario: Prohistoria.

Ghidoli, M. (2009). Biguá y otros dionisiacos. Intento de identificación de una pathosformel. Eadem Utraque Europa, (8), 73-92.

Hall, S. (2010 [1997]). The Spectacle of the 'Other'. En S. Hall (ed.), Representation: cultural representations and signifying practices. (pp. 223-286). London: Open University.

Harpham, G. G. (1982). On the Grotesque: Strategies of Contradiction in Art and Literature. New York: Princeton University Press.

Marin, L. ([1981] 2009). Poder, representación, imagen. Prismas, (13), 135-153.

Mitchell, W. T. J. ([1994] 2009). Teoría de la imagen. Madrid: Akal.

Moxey, K. (2003). Nostalgia de lo real. La problemática relación de la historia del arte con los estudios visuales. Estudios Visuales, (1), 41-59.

Quijada, M. (2000). El paradigma de la homogeneidad. En M. Quijada, C. Bernand, y A. Schneider, Homogeneidad y Nación con un estudio de caso: Argentina siglos XIX y XX. (pp. 15-55). Madrid: CSIC.

Szir, S. (2009). De la cultura impresa a la cultura de lo visible. Las publicaciones periódicas ilustradas en el siglo XIX. En: M. Garabedian, S. Szir y M. Lida, Prensa Argentina siglo XIX. Imágenes, textos y contextos. (pp. 53-83) Buenos Aires: Biblioteca Nacional/Teseo 
Thomson, P. (1972). The Grotesque. London: Methuen.

\section{NOTES}

1. Este trabajo ha sido realizado con el financiamiento del P. BID PICT $2014 \mathrm{n}^{\circ} 1211 \mathrm{y}$ en el marco del proyecto de Cooperación Internacional Bilateral Nivel I (PCB-I) CONICET-FAPERJ Res. 0010/14. 2. Para un análisis del tema en profundidad ver Mitchell (2009 [1994]).

3. Dibujante humorístico entre 1930 y 1940, volcándose especialmente en la creación de personajes para niños.

4. Dibujante e ilustrador de la primera mitad del siglo XX. Colaboró también en Billiken y Anteojito y realizó ilustraciones interiores para libros de la colección "Robin Hood".

5. Hago mención aquí de una investigación que propone que para la creación de los dibujos animados de las primeras décadas del siglo XX se acudió a convenciones visuales y performáticas de los blackface minstrelsy (Sammond 2015).

6. Un análisis en el contexto argentino de la década de 1940 puede verse en Geler (2015).

\section{AUTHOR}

\section{MARÍA DE LOURDES GHIDOLI}

Universidad de Buenos Aires, Argentina

Correo electrónico: marghidoli@gmail.com 